\title{
ESTIMATION OF THE PHYSICAL DISTANCE BETWEEN MAJOR GENOMIC MARKERS IN THE WERNER SYNDROME LOCUS (8pl1.2-12) BY DUAL-COLOR FISH ANALYSIS
}

\author{
Yoshiki Tokutake, ${ }^{1}$ Misako SatoH, ${ }^{1}$ Noriyuki SuzukI, ${ }^{1}$ \\ Masanobu Sugimoto, ${ }^{1}$ Minoru Sugawara, ${ }^{1}$ Makoto Goto, ${ }^{2}$ \\ and Yasuhiro FURUICHI ${ }^{1, *}$ \\ ${ }^{1}$ A GENE Research Institute, 200 Kajiwara, Kamakura 247, Japan \\ ${ }^{2}$ Tokyo Metropolitan Otsuka Hospital, 2-8-1 Minami-Otsuka, \\ Toshima-ku, Tokyo 170, Japan
}

\begin{abstract}
Summary The gene responsible for Werner syndrome (WS) is considered to be located between D8S131 and D8S87 in the 8p11.2-12 region that includes the closest marker D8S339 (Goto et al. (1992) Nature 355: 735-738). In this experiment, the order of major markers in this region was determined and the physical distances between them were estimated by dual-color fluorescence in situ hybridization (FISH) using P1, PAC and cosmid clone DNAs as probes. The fine overall order of telomereD8S131-D8S339-GSR-PP2A $\beta$-D8S283-D8S87-centromere was determined for the first time. The distance from D8S131 to D8S87 was estimated to be $1,634 \mathrm{~kb}$. To our surprise, the distance between D8S131 and D8S87 is much shorter than previously estimated by recombination analysis, $8.3 \mathrm{cM}$ equivalent to $8.3 \mathrm{Mb}$ in physical distance. These information provide the basis for the positional cloning of WS gene and the identification of its mutation.

Key Words Werner syndrome, FISH, physical distance, polymorphic markers
\end{abstract}

Werner syndrome (WS) is a rare autosomal recessive human disorder characterized by premature aging in young adults with several features of normal aging (Epstein et al., 1966). The identification of WS mutation (WRN) is not only essential to elucidate the etiology of WS but also it may be important in understanding the mechanisms underlying normal aging.

Goto et al. (1992) reported the close genetic linkage of WRN to a group of polymorphic markers, including D8S87 and ANK1, on the short arm of chromo-

Received February 13, 1996; Revised version accepted June 6, 1996.

* To whom correspondence should be addressed. 
some 8. They suggested that WRN lies between D8S87 and ANK1. Thomas et al. (1993) further extended this result and found that a dinucleotide repeat polymorphic marker, D8S339 (WT251), is located near to WRN at a recombination fraction of 0.006 with a lod score of 16.5. Other research groups (Schellenberg et al., 1992; Nakura et al., 1994) also reached a similar conclusion that WRN locus is between D8S131 and D8S87 in an 8.3-cM interval containing D8S339. Later, Oshima et al. (1994) also confirmed that the WRN occurs in chromosome

Table 1. List of P1, PAC and cosmid DNAs used as probes for FISH.

\begin{tabular}{clc}
\hline Clone No. & Source & Genomic marker \\
\hline 4478 & P1 & D8S131 \\
2587 & P1 & D8S339 \\
3349 & P1 & GSR \\
4117 & P1 & PP2AB \\
4030 & P1 & D8S283 \\
3687 & P1 & D8S87 \\
4738 & P1 & - \\
5980 & PAC & - \\
6044 & PAC & - \\
6463 & P1 & - \\
4892 & P1 & - \\
115 & cosmid & - \\
175 & cosmid & - \\
176 & cosmid & - \\
185 & cosmid & - \\
\hline
\end{tabular}

Cosmids $115,175,176$ and 185 (Kurimasa et al., 1995) were kindly donated by Dr. M. Oshimura of Faculty of Medicine, Tottori University. P1 phage DNAs containing human chromosome $8 \mathrm{p}(11.2-12)$-specific genomic markers were screened from $\mathrm{P} 1$ phage library by Genome System Co., Ltd., St. Louis and were purified by us by ultracentrifugation with $\mathrm{CsCl}$ density gradient.

Genomic markers enlisted are present on the corresponding DNA clones.

Fig. 1. FISH using various markers of Werner syndrome locus on chromosome $8 \mathrm{p}$. (A) The signals of biotin-labelled P1 (No. 4030) DNA probe (green) are seen near to the D8Z2 signal, a reference marker of centromere of chromosome 8. (B) Interphase nuclei hybridized with No. 4030 (green) and No. 3349 (red) probes. FISH was carried out essentially by the methods previously described by Saltman et al. (1993) and Westbrook et al. (1994) using the DNA probes listed in Table 1. Peripheral blood cells were stimulated with phytohemagglutinin, and mitosis was stopped at metaphase with $50 \mathrm{ng} / \mathrm{ml}$ colcemide. They were then collected and fixed with an acetic acid/methanol $(1: 3)$ solution and were spread on a glass slide. All probes were labelled either with biotin-16dUTP or digoxigenin-11-dUTP by nick-translation and purified with nickcolumn before hybridization. Results of dual-color FISH experiments were evaluated on a Nikon Optiphoto fluorescent microscope. Each signal was detected simultaneously, independently elaborated and the final projections were superimposed by a Mac-Probe Ver. 2.5 software (Perceptive Scientific Instrument, Inc., Texas). 


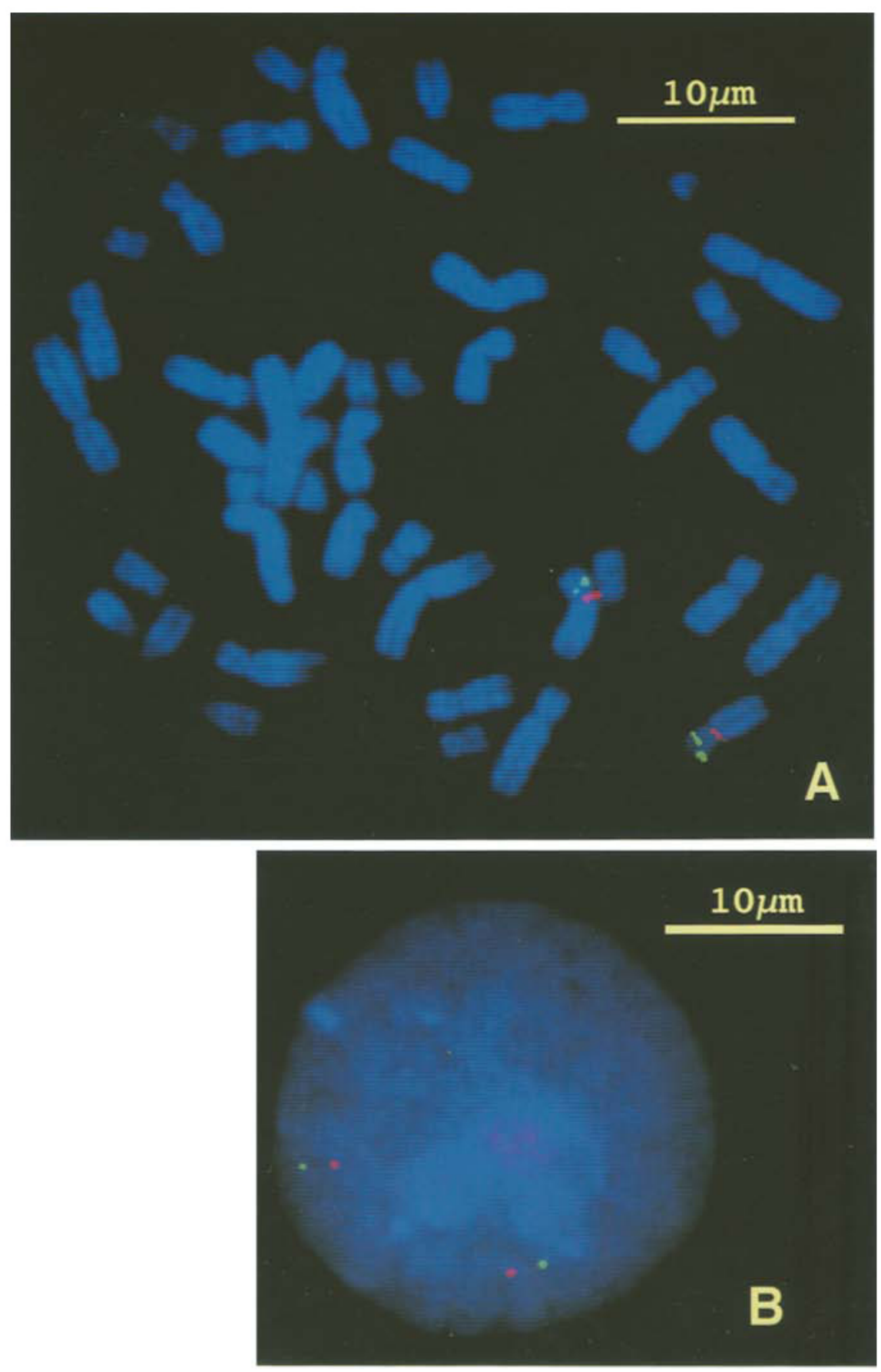

Fig. 1 
8p11.2-12 based on the radiation hybrid mapping experiments.

In this study, we took a visible approach to determine the order of major markers located in this region and to estimate the physical distance between them by fluorescence in situ hybridization (FISH) using P1, PAC and cosmid clones as probes. Before estimating the distance between various DNA clones, we first examined whether each cloned DNA is indeed present on the short arm of chromosome 8 with the use of metaphase chromosomes. All the DNAs of P1, PAC and cosmid clones used as probes (Table 1) were confirmed to be located on the short arm of chromosome 8 . Figure $1 \mathrm{~A}$ shows such a representative result. The green signal of the No. 4030 probe was located near the red signal of the D8Z2 probe which is the standard marker of centromere of chromosome 8 (Fig. 1A). Figure 1B shows the data of an interphase nucleus with two pairs of red (No. 3349) and green (No. 4030) signals.

Van den Engh et al. (1992) reported that there was a linear correlation

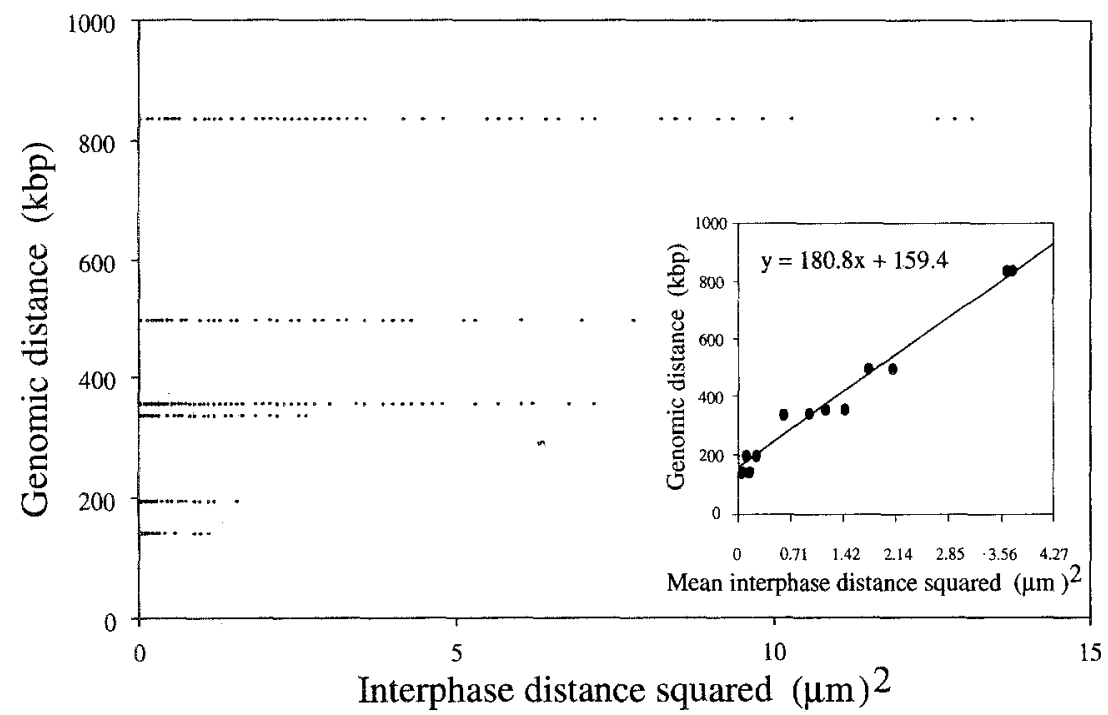

Fig. 2. Distribution of intervals of genetic markers measured by dual-color FISH with interphase nuclei. About 40 distances were measured by dual-color FISH under the fiuorescent microscope. Their squared values were plotted on the horizontal axis from their genomic sizes shown on the vertical axis. Six instances of measurement are represented in the figure. They are for Nos. 25873349 (140 kb), Nos. 3349-4117 (194 kb), Nos. 2587-4117 (335 kb), Nos. 3349$4030(356 \mathrm{~kb})$, Nos. 2587-4030 (497 kb) and Nos. 2587-3687 (819 kb). Inset: The mean interphase distances squared $\left(\mu \mathrm{m}^{2}\right)$ were plotted along with the intervals of genomic markers $(\mathrm{kbp})$ which were calculated from the length of PI DNAs constituting contig. The results obtained with a Japanese male and a female were shown. The linear line is concordant with the equation $(y=$ $180.8 x+159.4)$ placed in the figure. 
between the square of the mean interphase distance estimated by FISH and the known genomic distance. We constructed a partial contig of $\mathrm{P} 1$ clones spanning about $500 \mathrm{~kb}$ between D8S339 and D8S283 (the contig will be published elsewhere after completion). Based on this contig, distances between Nos. 2587-3349, 3349$4117,2587-4117,3349-4030$ and $2587-4030$ were calculated to be $140 \mathrm{~kb}, 194 \mathrm{~kb}$, $335 \mathrm{~kb}, 356 \mathrm{~kb}$ and $497 \mathrm{~kb}$, respectively, and were used as the standards for estimating the order and the distance of other genetic markers. The values represent the intervals from the middle portions of two P1 DNAs. Employing the P1 DNAs as probes for FISH, we confirmed that there is a linear correlation between the two parameters which is expressed by the following equation: $y=180.8 x+$ 159.4, where $y$ is the genomic distance $(\mathrm{kb})$ and $x$ is the mean interphase distance squared $\left(\mu \mathrm{m}^{2}\right)$. The distribution of distances (interphase distance squared $\left(\mu \mathrm{m}^{2}\right)$ ) resulting from about 40 samples examined was shown in Fig. 2. The inset figure shows a linear correlation between the genomic distances and mean values of measured distances squared.

First, we determined the distance between two cloned P1 DNAs, No. 4030 DNA (containing D8S283 marker) and No. 3687 DNA (containing D8S87 marker), by the dual-color FISH. The distance between the two clones was found to be $334 \mathrm{~kb}$. Meanwhile, the No. 4117 DNA containing PP2A $\beta$ gene was known to be located telomeric to No. 4030 DNA from our earlier efforts in contig formation (unpublished observation). With this notion and with the distance between No. 4030 and No. 3687 DNAs, which was found shorter than the interval between No. 4117 and No. 3687 DNAs, the No. 3687 DNA was found to be located on the centromeric side of No. 4030 DNA.

Second, the duplicate determinations of the distance between the FISH signals of No. 2587 and No. 3687 probes gave rise to $1.91 \mu \mathrm{m}$ for a Japanese male and 1.92 $\mu \mathrm{m}$ for a Japanese female (a mean value of $1.91 \mu \mathrm{m}$ ). When this value was squared

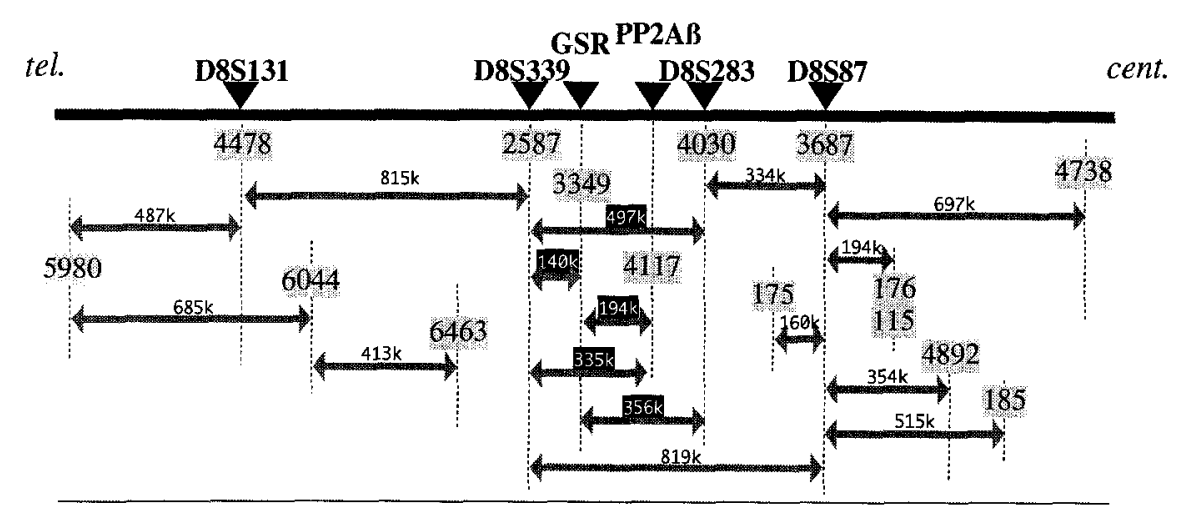

Fig. 3. Physical distance between genomic markers in the WRN locus. The distances obtained from the contig were shown by inverted letters while the distances measured by FISH were shown by normal letters. 
and plotted on the extrapolated line of inset figure of Fig. 2, a distance of $819 \mathrm{~kb}$ was obtained, which coincided well with the sum of the distances between Nos. 2587-4030 and Nos, 4030-3687 DNAs $(497 \mathrm{~kb}+334 \mathrm{~kb}=831 \mathrm{~kb})$. These results indicated that our standard ruler to measure the distance is applicable to at least $800 \mathrm{~kb}$.

The distance between No. 4478 (containing D8S131 marker) and No. 2587 (containing D8S339 marker) DNAs was estimated in the same way to be $815 \mathrm{~kb}$. Since the distance between No. 4478 and No. 4117 was found to be longer than the distance between No. 4478 and No. 2587, it was concluded that No. 4478 is located telomeric to No. 2587, and the order of these P1 DNAs is telomere-No.4478-No. 2587-No.4117-centromere. Similarly, the No. 3349 DNA (containing the GSR marker) was found to be located centromeric to D8S339, and the No. 4117 DNA (harboring PP2A $\beta$ gene marker) was found to be also centromeric to D8S339. Collectively, Fig. 3 demonstrates the distances between other markers in the P1, PAC or cosmid clones, and the order of genetic markers in this region i.e., telomere-D8S131-D8S339-GSR-PP2A $\beta$-D8S283-D8S87-centromere.

In this study, the region between D8S131 and D8S87 markers was estimated to be approximately $1.6 \mathrm{Mb}$ in length with D8S339 located almost in the middle of the two markers. This distance is much shorter than previously estimated by recombination frequencies, i.e. $8.3 \mathrm{cM}$ (sex averaged distance) (Oshima et al., 1994). Furthermore, according to this estimation, D8S339 is supposed to be located relatively closer to D8S87 (Nakura et al., 1994); that is, the distance between D8S131 and D8S339 is $6.7 \mathrm{cM}$, while the interval of D8S339 and D8S87 is $1.6 \mathrm{cM}$.

By contrast, the more recent analysis by Oshima et al. (1994) with a $10,000-$ rad radiation-reduced hybrid $(\mathrm{RH})$ cell panel gave a result similar to ours for the location of D8S339; D8S339 was positioned around the middle of D8S131 and D8S87. Moreover, the distance of $112.3 \mathrm{cR}_{10,000}$ (equivalent to $1.57 \mathrm{Mb}$ ) was estimated by RH mapping for D8S131 and D8S87. It was almost identical to our estimation, indicating that the present method using dual-color FISH is straightforward and compatible in the distance measurement with the RH mapping method.

For positional cloning, construction of a complete vector contig covering the region and the accurate distance measurement are important. Present studies provide the basis to these purposes.

Acknowledgments We thank Dr. K. Ichikawa, Dr. T. Matsumoto, Mr. A. Shimamoto, Ms. Y. Yamabe, Ms. S. Kitao, Mr. O. Imamura and Ms. K. Sugawara for their help and contribution to this work, and Ms. A. Fujii for her help for preparing the manuscript.

Note added in proof After submitting this paper, Yu et al. (1996) have cloned the WS gene from the region D8S339 and D8S87. This gene represents a high homology to the RecQ DNA helicase gene and is mutated in $60 \%$ of Japanese WS patients. 


\section{REFERENCES}

Epstein CJ, Martin GM, Schultz AL, Motulsky GG (1966): Werner's syndrome. A review of its symptomatology, natural history, pathologic features, genetics and relationship to the natural aging process. Medicine 45: $177-221$

Goto M, Rubenstein M, Weber J, Woods K, Drayna D (1992): Genetic linkage of Werner's syndrome to five markers on chromosome 8. Nature 355: 735-738

Kurimasa A, Suzuki N, Kumano S, Li H, Wells D, Wagner MJ, Chen F, Chen DJ, Oshimura M (1995): Construction of 110 cosmid markers and a $4.5 \mathrm{Mb}$ YAC contig on human chromosome 8p12-q11.1. Genomics 28: 147-153

Nakura J, Wusman EM, Miki T, Kamino K, Yu C-E, Oshima J, Fukuchi K, Weber JL, Piussan C, Melaragno MI, Epstein CJ, Scappaticci S, Fraccaro M, Matsumura T, Murano S, Yoshida S, Fujiwara Y, Saida T, Ogihara T, Martin GM, Schellenberg GD (1994): Homozygosity mapping of the Werner syndrome locus (WRN). Genomics 23: 600-608

Oshima J, Yu CE, Boehnke M, Weber JL, Edelhoff S, Wagner MJ, Wells DE, Wood S, Disteche CM, Martin GM, Schellenberg GD (1994): Integrated mapping analysis of the Werner syndrome region of chromosome 8. Genomics 23: 100-113

Saltman DL, Dolganov GM, Warrington JA, Wasmuth JJ, Lovett M (1993): A physical map of 15 loci on human chromosome 5q23-q33 by two-color fluorescence in situ hybridization. Genomics 16: 726-732

Schellenberg GD, Martin GM, Wijman EM, Nakura J, Miki T, Ogihara T (1992): Homozygosity mapping and Werner's syndrome. Lancet 339: 1002

Thomas W, Rubenstein M, Goto M, Drayna D (1993): A genetic analysis of the Werner syndrome region on human chromosome 8p. Genomics 16: 685-690

Van den Engh G, Sachs R, Trask BJ (1992): Estimating genomic distance from DNA sequence location in cell nuclei by a random walk model. Science 257: 1410-1412

Westbrook CA, LeBeau MM, Neuman WL, Keinanen M, Yamaoka LH, Speer MC, Espinosa R, Nakamura Y, Williamson R, Mullan M, Buetow K (1994): Physical and genetic map of 5q31: use of fluorescence in situ hybridization data to identify errors in the CEPH database. Cytogenet Cell Genet 67: 86-93

Yu CE, Oshima J, Fu YH, Wijisman EM, Hisama F, Alisch R, Matthews S, Nakura J, Miki T, Ouais S, Martin GM, Mulligan J, Schellenberg GD (1996): Positional cloning of the Werner's syndrome gene. Science 272: 258-262 